\title{
The natural capital of city trees
}

Katherine J. Willis, Royal Botanic Gardens, Kew, Richmond, Surrey, TW9 3EA, UK \& Long-term Ecology Laboratory, Department of Zoology, University of Oxford, OX1 3PS, UK.

Gillian Petrokofsky, Long-term Ecology Laboratory, Department of Zoology, University of Oxford, OX1 3PS, UK

The term "natural capital" refers to elements of nature that, directly or indirectly, produce value for people. Determining the location and quality of natural capital assets, and the ecosystem services that they provide for human well-being, is now underway in many countries, not just in the countryside but also across cities. One example of such natural capital is provided by city trees, which can take up substantial amounts of carbon dioxide (1) and also cause local cooling, thereby ameliorating the urban heat island effect (2). City vegetation can also reduce pollution and improve human health. However, understanding the characteristics of particular species is critical, and planting the wrong species in the wrong places can cause unintended problems.

Some tree species are more pollution-resistant than others. For example, the London plane (Platanus $x$ hispanica) has thrived alongside city streets for many years, partly because it has an inbuilt pollutant-cleansing process through its ability to shed its bark. Vegetation can also act as a natural filter, removing particulate matter (PM) from the air either through the interception of airborne particles or the uptake of gaseous air pollution via stomata on the leaf surface (3). The amount of PM removed, however, largely depends on the species. For example, Chen et al. recently showed that the effectiveness of different plant species in removing PM from Beijing's air (and thus their potential for helping to reduce the severe smog that plagues the city every winter) varied by up to 14 times between species (4).

The main reasons for this variation were differences in leaf surface area, quantity of foliage cover, and physical shape of the species. Trees were most effective at removing PM, although tree height was important (shorter trees performed better). Good PM-removing trees included species of elm, magnolia, ash, and holly. Certain species of climbing vines performed better than some trees for PM capture, an important consideration when creating green walls and green roofing on city structures. Those not so effective at PM capture included some common street species, such as ginkgo (Ginkgo biloba) and honeysuckle (Lonicera maackii) (4).

Deciduousness of the trees is also important, as are the size, shape, and waxiness of the leaves. Sæbø et al. have reported that among 27 species of trees and shrubs commonly planted in Norwegian and Polish cities (5), coniferous species - in particular the Scots pine (Pinus sylvestris)are the most efficient at capturing PM. By contrast, broad-leaved deciduous species such as lime (Tilia cordata, the iconic "linden" tree of Berlin) were less efficient. An online tool developed to 
capture these data to assist with urban tree planting, i-Tree, developed by the U.S. Forest Service, is revealing some remarkable amounts of PM capture by different city trees. For example, a recent study using i-Tree estimated that the trees in public spaces in Strasbourg, France, removed 88.23 metric tons of pollutants between July 2012 and June 2013 (6).

In addition to pollution control, there is limited, but persuasive, evidence for positive effects of city trees on physical and mental health, which complements psychological research that has substantiated the benefits of parks and green spaces as health resources for urban populations (7). For example, when Kardan et al. compared neighborhoods with different densities of street trees in Toronto, Canada, with high-quality data sets on public health and demographics, they found that higher tree density (maple, locust, spruce, ash, linden, oak, cherry, and birch) was correlated with higher perception of health and lower incidence of heart and metabolic disease (8). The authors estimate that planting just 10 or more trees per city block is equivalent to saving more than $\$ 10,000$ Canadian dollars per household in health-related costs-a figure that far exceeds the estimated cost of planting and maintaining those additional 10 trees.

Similarly, Beyer et al. looked at a spectrum of urban to rural environments in Wisconsin, USA, and found, after controlling for a wide range of confounding factors, that having more trees in a neighborhood (measured as a higher percentage of tree canopy) was associated with more positive mental health, particularly among those aged 55 and older (9). Likewise, Taylor et al. found that in a cross-sectional study in London, UK, areas with higher rates of antidepressant prescription and prevalence of smoking had lower street tree densities. Smoking levels were linked to levels of antidepressant prescriptions, but after controlling for confounding factors, the relationship between number of trees and prescriptions to treat depression held (10).

A study analyzing the effects of the loss of city trees also provides compelling evidence for the benefits of trees for human health (11). Donovan et al. compared health data before and after the loss of 100 million ash (Fraxinus spp.) trees across 1296 U.S. counties between 1990 and 2007 due to infestation by the emerald ash borer (Agrilus planipennis). They found statistically significant increases in mortality related to cardiovascular and lower-respiratory tract illnesses. The magnitude of this effect increased as the infestation progressed. The authors concluded that tree loss was associated with increased mortality related to cardiovascular and lower-respiratory systems.

However, there is a downside. Some tree species can be associated with a number of problems, notably the release of airborne pollen that causes human allergic reactions and the emission of biogenic volatile organic compounds (BVOCs) associated with ozone formation. 
Trees belonging to the orders Fagales, Lamiales, Proteales, and Pinales are the most potent allergen sources (12). Many common urban trees belong to these orders, notably birch (Betula spp.), ash (Fraxinus spp.), mesquite (Prosopis juliflora), plane (Platanus spp.), and cypress (Cupressus spp.), raising the question of trade-offs between benefits and problems associated with some mass treeplanting initiatives in major cities including New York, London, and Shanghai. Trees in these campaigns are mostly chosen to reflect what is considered local, and although some advice is provided about issues such as poisonous fruit, there are almost no warnings about pollen allergy potential and other less visible health hazards (13). These initiatives also often neglect to take into account the production of BVOCs by street trees. Black gum (Nyssa sylvatica), poplar (Populus spp.), oak (Quercus spp.), false acacia (Robinia pseudoacacia), plane (Platanus spp.), and sycamore (Acer spp.) trees are all high BVOC emitters that are widely planted as street trees. There is a very real danger that $\mathrm{BVOC}$ releases could reverse the gains made in controlling anthropogenic emissions (14).

Finally, there is a problem with the shape of trees and their height. A number of studies have demonstrated that tall trees and dense vegetation can limit the circulation of air and trap PM at street level (4). In some cases, this aerodynamic effect might be more detrimental than the PM removal capacity of the trees. Platanus $x$ hispanica, for example, needs to be heavily pruned, because its dense structure otherwise results in poor air flow and causes PM to become trapped at street level (15).

Planting trees in cities can therefore have clear benefits, but also downsides. Understanding these trade-offs requires detailed knowledge of the species concerned and their suitability to the city. Ecological tolerances of trees must also be taken into account; tropical trees, for example, are unlikely to do well in boreal zones, and this will influence their functionality in cities outside their natural range. However, the list of tree species planted in cities is fairly limited, and beauty often takes precedence over science, with little regard paid to the full range of natural capital advantages and disadvantages of individual species (16). When searching for new potential candidates, diversity is important; although we often cannot guard against the next pathogen, ensuring that a wide range of different trees are planted will provide some resilience. It might be good to also consider rare, threatened, and endangered species. Ginkgo biloba was once one of the rarest and most critically endangered species in the world; its populations are now widespread globally, thanks to its use as a city tree.

\section{Funding source}

GP is funded by an EU LIFE+ grant

\section{References}

1. D. J. Nowak, S. Hirabayashi, A. Bodine, E. Greenfield, Tree and forest effects on air quality and human health in the United States. Environmental Pollution 193, 119 (2014). 
2. F. Kong, H. Yin, P. James, L. R. Hutyra, H. S. He, Effects of spatial pattern of greenspace on urban cooling in a large metropolitan area of eastern China. Landscape and Urban Planning 128, 35 (2014).

3. S. Janhäll, Review on urban vegetation and particle air pollution - Deposition and dispersion. Atmospheric Environment 105, 130 (2015).

4. L. Chen, C. Liu, R. Zou, M. Yang, Z. Zhang, Experimental examination of effectiveness of vegetation as bio-filter of particulate matters in the urban environment. Environmental Pollution 208, Part A, 198 (2016).

5. A. Sæb $\varnothing$ et al., Plant species differences in particulate matter accumulation on leaf surfaces. Science of The Total Environment 427-428, 347 (2012).

6. W. Selmi et al., Air pollution removal by trees in public green spaces in Strasbourg city, France. Urban For. Urban Green. 17, 192 (2016).

7. T. Hartig, P. H. Kahn, Living in cities, naturally. Science 352, 938 (2016).

8. O. Kardan et al., Neighborhood greenspace and health in a large urban center. Scientific Reports 5, 11610 (2015).

9. K. Beyer et al., Exposure to Neighborhood Green Space and Mental Health: Evidence from the Survey of the Health of Wisconsin. International Journal of Environmental Research and Public Health 11, 3453 (2014).

10. M. S. Taylor, B. W. Wheeler, M. P. White, T. Economou, N. J. Osborne, Research note: Urban street tree density and antidepressant prescription rates-A cross-sectional study in London, UK. Landscape and Urban Planning 136, 174 (2015).

11. G. H. Donovan et al., The Relationship Between Trees and Human Health: Evidence from the Spread of the Emerald Ash Borer. American Journal of Preventive Medicine 44, 139 (2013).

12. C. Asam, H. Hofer, M. Wolf, L. Aglas, M. Wallner, Tree pollen allergens-an update from a molecular perspective. Allergy 70, 1201 (2015).

13. K. R. Weinberger, P. L. Kinney, G. S. Lovasi, A review of spatial variation of allergenic tree pollen within cities. Arboriculture and Urban Forestry 41, 57 (2015).

14. G. Churkina, R. Grote, T. M. Butler, M. Lawrence, Natural selection? Picking the right trees for urban greening. Environmental Science \& Policy 47, 12 (2015).

15. S. Jin, J. Guo, S. Wheeler, L. Kan, S. Che, Evaluation of impacts of trees on PM2.5 dispersion in urban streets. Atmospheric Environment 99, 277 (2014).

16. J. Yang, Y. Chang, P. Yan, Ranking the suitability of common urban tree species for controlling PM2.5 pollution. Atmos. Pollut. Res. 6, 267 (2015). 